\title{
2 \\ Latino/a Immigration: A Refutation of the Social Trust Argument
}

\author{
José Jorge Mendoza
}

\section{Introduction}

In debating the politics and ethics of immigration, it is not uncommon to come across a version of the "social trust argument." The basic form of the argument is always the same. It contends that a political community cannot survive without social trust, and that social trust cannot be achieved or maintained without a political community having discretionary control over immigration.

Where social trust arguments diverge from one another, however, is on the matter of what social trust should be based on. For example, there is a version of the social trust argument that insists that social trust is (or should be) based on a shared race, ethnicity, or culture. According to this version of the argument, immigration dilutes or destabilizes social trust by introducing different races, ethnicities, or cultures into the political community (Grant 1922). In the late nineteenth and early twentieth century, this version of the social trust argument was often used to justify notoriously discriminatory US immigration policies, such as the 1882 Chinese Exclusion Act and the "national origin" quota introduced in 1924.

This version of the social trust argument has already received a lot of criticism, but most of objections leveled against it do not extend to more sophisticated versions of this argument. For example, there is another version of the social trust argument that suggests that social trust is (or should be) based on shared institutions (e.g., welfare services, social programs, and public education) and not on arbitrary factors such as race or ethnicity. This more sophisticated version of the social trust argument holds that a political community must have discretionary control over immigration because immigration threatens these shared institutions, either by undermining the faith people have in them or by straining them 
beyond their capacity. Today, US immigration policy eschews this earlier bigoted version of the social trust argument, but since the 1990s it has not shied away from adopting a more sophisticated version of this argument to justify its "enforcement first" approach to immigration reform. This has been the case at both the state level (Schuck 1995) and the federal level (1996 Illegal Immigration Reform \& Immigrant Responsibility Act; 1996 Personal Responsibility and Work Opportunity Reconciliation Act).

In this chapter, I offer a line of criticism directed at this more sophisticated version of the social trust argument. I begin by first explaining what the social trust argument is, what some of its critics have said about it, and how those criticisms have not succeeded in completely refuting it. Then, I look at the sociohistorical circumstances of Latino/as in the United States. The purpose of this investigation is to expose an inherent weakness of the social trust argument: it not only fails to deliver on its promise of social trust, but actually promotes its opposite, social mistrust. The later sections then make the case that a better way of promoting social trust, and at the same time abating social mistrust, is to circumvent a political community's ability to control immigration by giving priority to both sociohistorical circumstances and, at least in a minimalist sense, immigrant rights. If my argument is successful, it will show not only why the social trust argument is indefensible, but also why "enforcement first" approaches to immigration reform should be rejected in favor of a more comprehensive approach.

\section{The social trust argument}

The social trust argument is typically presented as a consequentialist argument. ${ }^{1}$ This means that proponents of the argument are not necessarily claiming that a political community is in some absolute sense entitled to social trust, but rather that without social trust, many unfortunate consequences will befall the political community. According to Shelley Wilcox, the social trust argument can be articulated in one of two ways. First, it can be argued that newcomers are not sufficiently integrating into their receiving societies and therefore "...embracing large numbers of unacculturated immigrants will disrupt the cultural conditions that enable citizens to act autonomously" (Wilcox 2004, 559). Or, secondly, it can be argued that: "... the presence of ethnically diverse immigrants will diminish the strong sense of national solidarity that is necessary to sustain vital liberal democratic ideals [and institutions]" (Wilcox 2004, 559). In either case, the result would be the same: if a political community lacks discretionary control over immigration, then social trust, which 
is instrumentally necessary to sustain political autonomy and/or liberal principles, values, and institutions, will be undermined.

Along similar lines, Ryan Pevnick has explained the dilemma of social trust in the following way. Most advocates of open borders justify their position by appealing to some version of moral egalitarianism, ${ }^{2}$ which is a position that believes that all persons deserve equal moral consideration. However, another egalitarian commitment is that institutions ought to provide distributive and/or redistributive justice (i.e., provide welfare services, social programs, and public education). According to Pevnick, proponents of the social trust argument see a problem here: “... citizens will refuse to support justice-required redistributive programs if such programs incorporate nationally diverse immigrants" (Pevnick $2009,156)$. If it is the case that citizens will only support institutions of distributive and/or redistributive justice if those institutions help only their fellow citizens, then "... egalitarian liberals cannot have their cake and eat it too; instead, they must choose which commitment-increased immigration or redistributive programs-takes precedence and accept that they will have to abandon the other" (Pevnick 2009, 148). The point here is that there is no inconsistency, as most open-borders advocates have suggested, in justifying a political community's discretionary right to control immigration from an egalitarian perspective (Pevnick 2009,148 ).

Neither Wilcox nor Pevnick subscribe to the social trust argument and both have raised their own objections to it. Pevnick, for example, has argued that: "the trust on which the welfare state relies depends more on the shape of the institutions than on the identity of the population that they serve" (Pevnick 2009, 148). In other words, the social trust that bolsters these institutions depends less on the particular individuals who make up the political community, than it depends on institutions giving off the appearance of fairness. For example, if the individuals who benefit from these institutions are recognized as individuals who have contributed, or will contribute, to them, then the institutions seem to be operating as they should and people will have faith in them.

Going a step further, Pevnick also notes that: "even if successful, the social trust argument can only provide reason to limit claims of membership. The social trust argument provides no reason to forbid migrants from entering the territory" (Pevnick 2009, 156-157 emphasis in original). In other words, for Pevnick, citizenship and residency are, at least analytically, two distinct things. So whatever discretion the social trust argument might grant to political communities, that discretion is limited to claims of citizenship and not to claims of residency. This leaves open 
the possibility that while the social trust argument might be sufficient to show why a political community ought to have the discretionary right to control citizenship, it does not show why it ought to have the same discretion over residency.

For her part, Wilcox makes the case against the social trust argument from a liberal democratic point of view. According to Wilcox, in a liberal democracy a thick national identity (i.e., an identity that functions as both a political and cultural identity) will not only be unnecessary, but will also be undesirable and even unjustifiable. On these grounds, Wilcox proposes that a better, and more consistent (at least more consistent with liberal democracy) way of obtaining and maintaining social trust is through "a non-nationalist model of naturalization that would encourage immigrants to become integrated into liberal democratic societies by participating in their major economic and sociopolitical institutions and practices" (Wilcox 2004, 560).

While I am sympathetic to both of these responses and find them both persuasive, their applicability is restricted to cases wherein liberal commitments (e.g., respect for individual liberty and universal equality) are already in place. As it turns out, most supporters of the social trust argument either do not harbor these commitments or at least do not prioritize them in the same way that liberals do. Supporters of the social trust argument are, by and large, more nationalist and/or communitarian in their moral and political commitments. These commitments tend to generate thicker notions of citizenship, or at least thicker than what most liberals would be comfortable with. These thicker notions of citizenship exclude the possibility that residency can or ought to be delinked from citizenship or that non-nationalist models of naturalization would be sufficient for political integration. In short, it seems that proponents of a thinker version of the social trust argument could withstand the sorts of liberal objections being raised by Wilcox and Pevnick, by maintaining that the alternatives provided by Wilcox and Pevnick would not generate the kind of social trust that is necessary for the continued existence of the political community.

Arguably one of the most well-known proponents of this thicker version of the social trust argument is Samuel P. Huntington. Huntington's version of the social trust argument can be found in his second major work, Who Are We?, in which he defends the controversial claim that the United States is fundamentally an Anglo-Protestant nation. By AngloProtestantism, Huntington has in mind a certain type of "culture," which falls somewhere between an ethnicity and a civic identity. As he writes: 
Hence there is no validity to the claim that Americans have to choose between a white, WASPish ethnic identity, on the one hand, and an abstract, shallow civic identity dependent on commitment to certain political principles, on the other. The core of their identity is the culture that the settlers created, which generations of immigrants have absorbed, and which gave birth to the American Creed. At the heart of that culture has been Protestantism. (Huntington 2004, 62)

Huntington's central contention, which is expressed in this passage, is that besides being an Anglo-Protestant nation, the United States is also a settler nation and not a nation of immigrants. In fact, he goes on to argue that Americans have historically not liked immigrants and that they "... did not celebrate their country as a "nation of immigrants'" (Huntington 2004, 38). The distinction Huntington draws between a settler nation and a nation of immigrants is that: "settlers leave an existing society... They are imbued with a sense of collective purpose. Implicitly or explicitly they subscribe to a compact or charter that defines...the community they create..." (Huntington 2004, 39). Immigrants, according to Huntington, do not do these things because their migration from one society to another is a very personal process, and for that reason they are not interested in forming compacts (Huntington 2004, 39-40). Huntington uses these points to justify his claim that, in the twenty-first century, the biggest threat to the national unity (i.e., social trust) of the United States is immigration from Latin America and, in particular, from Mexico. As he writes:

The continuation of high levels of Mexican and Hispanic immigration plus the low rates of assimilation of these immigrants into American society and culture could eventually change America into a country of two languages, two cultures, and two peoples. This will not only transform America. It will also have deep consequences for Hispanics, who will be in America but not of it... There is no Americano dream. There is only the American dream created by an Anglo-Protestant society. Mexican-Americans will share in that dream and in that society only if they dream in English. (Huntington 2004, 256)

There are some serious doubts as to whether Huntington's account is correct (Kaag 2008; Orosco 2008, 16-19). Nonetheless, it is his version of the social trust argument that we should consider because, in contrast to Wilcox and Pevnick, Huntington believes that social trust requires more than having the right civic institutions; it also requires that individuals 
have something akin to the right "culture." While this argumentative move allows Huntington to avoid the objections raised by Wilcox and Pevnick, it also exemplifies for many the problem that has historically haunted the social trust argument: at its core this is really an argument that aims at, or is driven by, racial, ethnic, or cultural animus.

This is a problem because, on the one hand, a sure way of fomenting social mistrust is by ostracizing a particular segment of the political community (i.e., discriminate against people based on race, ethnicity, nationality, sex or gender). On the other hand, if social trust requires the promotion of the right kind of "culture," then a political community should, as Huntington suggests, be free to deny entry to those (e.g., Mexican immigrants) whom it sees as promoting the wrong kind of "culture." For example, while the United States currently has no "cultural" restrictions on immigration, there are many politicians who actively oppose immigration on grounds that certain immigrants (e.g., immigrants from Latin America) bring with them a kind of criminal culture that would undermine social trust. For example, Iowa Congressman Steve King has suggested: "For [every immigrant] who's a valedictorian, there's another 100 out there that-they weigh 130 pounds and they've got calves the size of cantaloupes because they're hauling 75 pounds of marijuana across the desert" (Wilstein 2013). Representative King's views on Latino/a immigrants are not merely reprehensible; they also breed mistrust of the entire Latino/a community, regardless of whether they are or are not citizens.

This is where we find the rub: promoting social trust in Huntington's thicker sense allows one to avoid the criticisms of Wilcox and Pevnick, but it does so only at the expense of promoting immigration policies that breed a kind of social mistrust (i.e., ostracizing a certain segment of the citizenry as permanent national outsiders).

A cynical-although not totally unfounded-response to Huntington's version of the social trust argument is that it should not be taken seriously at all. This cynical response suggests that the discriminatory implications of his social trust argument are not accidental or peripheral, but are a core part of all social trust arguments. They claim that the social trust argument is merely an attempt by nativists and xenophobes to justify (either to themselves or to others) their own irrational dislike of immigrants and have little to do with social trust. Edwina Barvosa articulates such a view when she states: “...identity contradictions and fragmentations within the psyches of some, if not many, mainstream white Americans underlie persistent patterns of anti-immigrant hostility..." (Barvosa 2012, 20). She goes on to say that the result of these psychic fragmentations is "... a 
political quagmire in which reason-based public deliberation is stymied by mass reactivity arising from the activation of constructed identity contradictions, unrecognized mass melancholia, residual trauma, or other intra-psychic fragmentations" (Barvosa 2012, 20). In other words, proponents of the social trust argument are not so much trying to stake out a reasonable position on immigration policy; they are attempting to justify their own persistent patterns of racial, ethnic, or cultural resentment. Therefore, Barvosa would claim, it is no wonder that a position like Huntington's suffers from a contradiction, of attempting to promote social trust in a way that is sure to foment social mistrust, because it is based on an irrational hatred and not on a rational evaluation of immigration policy.

An analysis like Barvosa's is helpful in both exposing and explaining the discriminatory potential of a Huntington's version of the social trust argument. That said a more philosophically sophisticated version of the social trust argument might still be able to avoid these irrationalities and thereby survive a Barvosa-style critique. For example, some proponents of the social trust argument, like David Miller, have recognized the discriminatory potential of the social trust argument and have tried to immunize their own position against these noxious entailments. Miller, like Huntington, believes that maintaining a political community (even, and especially, a liberal state) will "require a common public culture that in part constitutes the political identity of their members" (Miller 2005, 199). Unlike Huntington, however, Miller explicitly rejects the possibility that a political community can use such things as race, ethnicity, sex or gender as criteria for exclusion because: "to be told that they belong to the wrong race, or sex... is insulting, given that these features do not connect to anything of real significance to the society [potential immigrants] want to join" (Miller 2005, 204).

Assuming for the moment that something like Miller's anti-discriminatory addendum would allow for a version of the social trust argument that can (a) skirt the initial criticisms of Wilcox and Pevnick and (b) avoid the discriminatory potential that makes Huntington's version so repulsive, would this be sufficient to salvage the argument? At first glance it seems that this might do the trick. After all, if admissions and exclusions criteria are nondiscriminatory and treat everyone equally, how could they possibly be the source of social mistrust?

The remainder of this chapter will make the case that, even if proponents of the social trust argument come to adopt something like Miller's addendum, the argument is still not salvageable. Its two conflicting components (viz., a political community's discretionary control over 
immigration and the need for social trust) remain at odds with each other. So while it is true that social trust depends largely on how a political community deals with immigration, proponents of the social trust argument have either misidentified or overlooked an important source of social mistrust. In the next section I will shed some light on this source by briefly exploring the case of Latino/as in the United States.

\section{The curious case of Latino/as in the United States}

This section outlines some of the key flashpoints in US immigration policy and how they have affected the Latino/a community. Understanding the historical relationship between the Latino/a community and US immigration policy is important because it exemplifies the two claims that this chapter is attempting to establish: (1) the social trust argument, even when it adopts something like Miller's addendum, still fails to provide social trust, and (2) avoiding social mistrust necessitates that the control a political community has over immigration be circumvented and not discretionary.

Most historians would probably concede that US immigration law and policy reached its discriminatory zenith in the early part of twentieth century. By 1900 the Chinese Exclusion Acts were not only the law of the land, but they had survived various Supreme Court challenges (see Chinese Exclusion Act 1882; Chae Chan Ping v. United States 1889; Fong Yue Ting v. United States 1893). In 1917 this race-based form of exclusion was further expanded to include most of Asia, which subsequently came to be known as the "Asiatic barred zone" (1917 Immigration Act). Then, in 1924, the Johnson-Reed Act barred from entry all immigrants who were ineligible for US citizenship and also introduced a system of "national origin" quotas (1924 Immigration Act).

The provisions of the 1924 Act were perniciously discriminatory in two ways. First, they made most nonwhite persons ineligible to enter the United States because, as far back as the-1790, naturalized US citizenship had alreadybeen restricted to "white persons" (1790 Naturalization Act). After the 1924 Act went into effect, nonwhite persons were not only barred from obtaining US citizenship, but were also denied admission into the United States. Second, the "national origin" quota did not apply equally to all nations. The quota was intended to reflect the true composition of the United States, and based on this mandate Congress felt justified in using the 1890 census, which took place just before a large wave of immigrants from eastern and southern Europe came to the United States, to determine the quota numbers. Not surprisingly, the 1924 Act allocated 
higher quota numbers to northern Europeans and very few to eastern or southern Europeans (Ngai, 2004, 23).

Interestingly enough, these overtly discriminatory laws and policies did not place any restrictions on countries from the Western hemisphere, which made Latino/a immigrants different from other immigrants. At a time when nonwhite persons were routinely being denied membership and entry into the United States, Mexican nationals were not only being allowed to enter the United States, but in many cases were even eligible for US citizenship (De Leon 1979).

This is not to say that at the turn of the twentieth century Latino/ as in the United States did not face social ostracism and discrimination. Despite their eligibility to enter and become US citizens, the nonwhite, non-northern European status of people with Mexican ancestry still branded them as national outsiders and even subjected them to unjust forms of deportation (see Johnson 2005) and even violence (see Delgado 2009). The larger point, however, still seems to hold: at the turn of the twentieth century, the social positioning of Latino/as in the United States was not necessarily worse and in some cases (e.g., with respect to immigration and citizenship eligibility) might have been better than that faced by other similarly situated ethnic groups we now consider "white" (e.g., Irish, Italian, Poles, and Jews).

Beginning in 1943, with the repeal of the Chinese Exclusion Act (Magnuson Act 1943), and culminating in 1965, when the "national origins" quota was replaced with a system of numerical caps (1965 Immigration and Nationality Act), the more noxious (i.e., Huntingtonlike) aspects of US immigration policy were supposed to have come to an end. Admissions and exclusions criteria were no longer supposed to be discriminatory (thereby satisfying Miller's anti-discriminatory addendum), so it should have been the case that they would not generate the type of social mistrust that is commonly associated with xenophobic immigration laws and policies.

For members of the aforementioned "white" ethnic groups this was in fact the case. As the United States came to embrace a "nation of immigrants" narrative, "white" ethnic groups were able to obtain national insider status (see Gabaccia 2010). Interestingly enough, however, these same anti-discriminatory immigration reforms seemed to have the opposite effect on the Latino/a community. Post-1965, the association of Latino/as with being national outsiders gained in strength (see De Genova 2004). This presents us with a strange turn of events. Where, at the turn of the twentieth century, Mexican nationality could provide a noncitizen with at least some reprieve from the discriminatory nature of 
US immigration controls, now, at the start of the twenty-first century, we have a situation where a hint of Latin American ancestry is sufficient to arouse suspicion of one's civic standing and thereby them as a threat to national unity (i.e., a threat to social trust).

So what explains the deteriorating social standing of the Latino/as in the United States, especially during a time when similarly situated ethnic groups saw their standing drastically improve? One could make the argument that the reason today's "white" ethnic groups (e.g., people of Irish, Italian, Polish, and Jewish descent) were able to gain a kind of national insider status while other groups (e.g., people of Asian and Latin American descent) were not was because of the way "whiteness" functions. On this view, ethnic groups that are today considered "white" in the United States were not fully white before 1965 . Prior to 1965 , their status was somewhere between "white" and nonwhite. However, those ethnic groups that are today considered nonwhite (e.g., Asian-Americans and Latino/as) are groups that have always unambiguously fallen on the nonwhite side of this divide. This view goes on to claim that, while various factors played a role in transforming those in the "in-between" category to full "white" status, the aforementioned immigration reforms played a primary role in making this transformation possible (see Roediger 2006).

The strength of such an account is that it helps to explain why certain groups, for example Asian-Americans, did not suddenly gain social acceptance, even as the immigration restrictions that most directly affected them were being lifted. On this account, the ethnic groups that gained national insider status were those, and only those, who could potentially fall on the "white" side of this divide. Ethnic groups that did not have this same "in-between" status therefore could not benefit from changes to immigration law and thereby remained firmly entrenched on the nonwhite side of this divide.

The problem for an account like this, however, is explaining the curious case of Latino/as. If, at the turn of the twentieth century, there were an ethnic group in the United States that could be considered "in-between," it would likely have to have been Latino/as. When Irish, Italian, Polish, and Jewish immigrants were finding it difficult even to enter the United States, Latino/as were not only permitted to enter, but also had US courts recognize their eligibility for citizenship. So why, post-1965, did Latino/ as not also come to enjoy a national insider status as many of today's "white" ethnic groups do? Appeals to a lack of "whiteness" seem only to beg the question.

A more plausible explanation seems to be that, while these reforms treated all immigrants formally equal, they still left immigration control 
(specifically the enforcement of immigration laws) at the discretion of the political community, in this case at the discretion of the US federal government. If nondiscriminatory admission and exclusion policies were, by themselves, sufficient to neutralize their discriminatory potential, it stands to reason that post-1965 United States this is what we would have seen. Instead, as we see with the case of Latino/as, these reforms failed to ameliorate social mistrust. This suggests that Miller's addendum, while well intentioned, is still insufficient.

Nativists, such as Huntington, would argue that Miller's addendum fails to deliver on the promise of social trust because it gives the political community less, rather than more, discretion in the admission and exclusion of nonmembers. Miller's addendum, on their view, only handcuffs the political community in its attempts to foster the right "culture" (e.g., Anglo-Protestantism), which for them is essential to social trust. Therefore, from their perspective, it is not surprising that anti-discriminatory immigration reforms did not lead to social trust nor ameliorate social mistrust.

My position is that thinkers like Huntington are correct when they say that the national outsider status of groups like Latino/as in the United States is a threat to social trust and that political communities should address this. They are wrong, however, in believing that the solution to this problem is to give the political community more, rather than less, discretion in controlling immigration. The national outsider status that Latino/as are currently saddled with is not an essential feature of Latino/a-ness (as Huntington contends). This outsider status is the result of various factors, not the least of which is an immigration policy that did not sufficiently take into account sociohistorical circumstances or respect, even in a minimalist sense, immigrant rights.

The next two sections will therefore attempt to do two things: (1) explain what is meant by "sociohistorical circumstances" and "immigrant rights," and (2) suggest that an immigration policy that respects both of these is essential in developing social trust and ameliorating social mistrust. This is the critical point of the argument. If the promotion of social trust and the amelioration of social mistrust require that a political community's immigration policy adhere to these conditions, then the political community has, at best, a circumscribed-not discretionary-right to control immigration. In practical terms, this means that the "enforcement first" approach to immigration reform, which the United States has favored in recent years, might in fact be self-defeating and that a return to comprehensive approaches, especially those that mirror the recommendations made in the following two sections, should be adopted instead. 


\section{Sociohistorical circumstances and social trust}

The phrase "sociohistorical circumstances" is here used to mean the way the world really is, its real history, real international and global relations, and real material circumstances. This is obviously a very broad definition, but with regard to immigration the focus can be narrowed to the history, relations, and material circumstances that political communities have (or have had) with each other and with the individual members of each other's communities. Under this, admittedly broad, understanding of sociohistorical circumstances, we can see how adhering to them could take away some of the discretion that a political community has in controlling immigration.

For example, if we return to the case of the United States, we can see that, despite all the immigration reforms that were passed after 1943, the number of undocumented immigrants, specifically undocumented immigrants from Mexico, actually went up. The cause of this sudden increase could be attributed to various factors, but unquestionably a principle cause was the 1965 policy of numerical caps. These numerical caps placed a 20,000 persons per year cap on all nations, thereby treating all countries the same and removing the last reminisce of overtly discriminatory immigration restrictions. As already mentioned, however, before 1965 the United States had no limits on people migrating from the Western hemisphere. So, as Mae Ngai nicely summarizes:

The imposition of a 20,000 annual quota on Mexico recast Mexican migration as "illegal." When one considers that in the early 1960s annual "legal" Mexican migration comprised some 200,000 braceros and 35,000 regular admissions for permanent residency, the transfer of migration to "illegal" form should have surprised no one. The number of deportations of undocumented Mexicans increased by 40 percent in 1968 to $151,000 \ldots$ [by 1976] the INS expelled 781,000 Mexicans from the United States. Meanwhile, the total number of apprehensions for all others in the world, combined, remained below 100,000 a year (Ngai 2004, 261). In short, because of these numerical caps Latino/ as suddenly came to comprise a disproportionately large segment of the undocumented immigrant population, even though their actual numbers hardly changed.

So, similar to the way racial profiling assumes that nonwhites are criminals until they are proven innocent, since the late 1960s Latino/as in the United States have been assumed to be unlawfully present until 
their lawful status can be confirmed. While this is a fallacious way of reasoning-thinking that because Latino/as make up a disproportionate segment of the undocumented immigrant population, that therefore Latino/a identity is somehow a good marker of unlawful presence (i.e., affirming the consequent) - it is nonetheless an inference and association that is made in the United States and it is especially made by enforcement officers (see United States v. Brignoni-Ponce 1975 and United States v. Martinez-Fuerte 1976).

It should be obvious why this type of profiling is pernicious, even if it does result in better and more efficient enforcement of current immigration laws. It is pernicious because it breeds social mistrust among citizens, as most Latino/as in the United States are actually citizens, and constantly suspecting them of being improperly present puts their citizenship into doubt. ${ }^{3}$ To end or prevent these types of pernicious associations from forming, one of two things needs to happen. First, a way needs to be developed so that no one particular group within the larger political community comes to make up a disproportionate segment of the undocumented immigrant population. If this is done correctly, then these pernicious kinds of associations should never get off the ground. Alternatively, and likely in conjunction with the former, proactive measures need to be taken so that particular groups are not only not stigmatized by immigration law, but also not stigmatized in the enforcement of those laws. The way to address the former has to do with adhering to sociohistorical circumstances, so it will be the subject of the remainder of this section. The latter has more to do with immigrant rights, so it will be the subject of the section that follows.

If we recall, one of the problems with the post-1943 US immigration reforms was that they failed to adequately account for the 200,000+ annual migrants from Mexico. This failure served as a catalyst for the sudden increase in undocumented immigrants from Mexico because, even though the United States changed its immigration policy, its need for Mexican immigrant labor in the mid-1960s had not changed. The vast majority of Mexican immigrants, who were both needed by US employers and needed the jobs those employers offered, simply went from being legal migrants to being undocumented workers. This shift in the legal status of migrant workers is in large part what has led to the strong identification of Latino/as with being national outsiders (see De Genova 2004 and Chomsky 2014). Within the United States this identification has led to an increase, as opposed to a decrease, in the social mistrust of Latino/as. For example, Latino/as have come to be seen as unfairly using or straining beyond capacity the welfare services, social programs and 
public education of the United States, and this mistrust has served as the motivation for recent anti-immigrant state reforms, such as California's proposition 187, that prioritize enforcement by denying benefits to immigrants, but where the real target of the proposed law is the entire Latino/a community (Schuck 1995).

Therefore, if social trust-and not merely an immigrant-free environment-is the goal, then future US immigration reforms should have adhered to sociohistorical circumstances. For example, if it is a fact of the world that the US economy needs and will continue to draw immigrant labor from certain parts of the world (either because of its historical or geographical connections to this area or for other reasons), then US immigration policies ought to reflect this. The same can also be said about family relationships. This does not, however, entail that the United States must completely open its border. All it means is that if it seeks to reduce the number of undocumented immigrants in its territory, because large numbers of undocumented immigrants have the potential of fomenting social mistrust, then admissions policies need to take into account sociohistorical circumstances.

\section{Social trust requires immigrant rights}

Having immigration policies adhere to sociohistorical circumstances might limit a political community's ability to exclude immigrants, but it does not necessarily bring the social trust argument to an end. The fatal blow comes in the form of immigrant rights, especially if by immigrant rights we mean presumptive protections that limit a political community's right to expel noncitizens. If it turns out that these sorts of protections are necessary, even at a minimal level, to obtain social trust (or at least to not further foment social mistrust), then the social trust argument has been defeated. The difficulty, however, is in showing that proponents of the social trust argument are bound to accept such protections based on their own moral or political commitments.

As we already saw in the possible replies to Wilcox and Pevnick, proponents of the social trust argument tend to be more nationalist or communitarian in their moral and political commitments. This means that, unlike liberal cosmopolitans, they believe that there are some meaningful (i.e., moral or political) differences between citizens and noncitizens. For them, these differences make the denial of immigrant rights seem almost like common sense. After all, immigrants are not, or at least are not initially, citizens of the political community and therefore are not owed the same political, and maybe not even the same moral, consideration that is owed 
to other fellow citizens. So, even if citizens have the right to enter and remain within their own political community, as most nationalists and communitarians conceded that they do, immigrants are not owed the same courtesy. At best, immigrants might be granted the privilege to enter or remain within a political community, but that is at the discretion of that political community.

In this section, I challenge this conclusion by suggesting that social trust requires that a political community offer protections against overly intrusive immigration enforcement and that in order for these protections to be effective they also must extend to immigrants as well. The argument for this is as follows. While the social trust argument does not require a commitment to universal moral or political equality, it does demand respect for the moral and political equality of citizens. As we have already seen, a failure to respect the moral and political equality of citizens can relegate certain citizens to a kind of second-class status, which in turn undermines social trust. In short, there is no surer way of sowing the seeds of social mistrust than by undermining the moral or political equality of citizens.

There are many ways that the moral and political equality of citizens can be undermined, but as mentioned already, one sure way of doing so is to allow a certain group of citizens to bear a disproportionate amount of the burdens associated with enforcement. For example, if law enforcement agents disproportionately target nonwhite persons because they believe there is a strong link between being nonwhite and committing crime, then, regardless of how law enforcement agents might have come to make that association, the moral and political worth of nonwhite citizens has been undermined. These sorts of associations are therefore a source of social mistrust (specifically between white and nonwhite citizens). This means that if the end goal is social trust, then practices like racial profiling ought to be prohibited, even when prohibiting these practices might make law enforcement and crime fighting more difficult and less efficient.

Prohibiting these sorts of enforcement practices does not necessarily entail that laws cannot be enforced or that criminal activity must be tolerated. All that the preceding argument establishes is that, for the sake of social trust, the amount of discretion a political community has in enforcing its laws must be circumvented by what we might call an equality of burdens standard: whatever burdens result from the enforcement of laws, social trust requires that these burdens be allocated as equally as possible among all citizens, so that no citizen or group of citizens are given less moral or political consideration. As far as implications for immigration 
policy, the equality of burdens standard would merely ask for the nondiscriminatory element that is already present in US admissions and exclusions policy to be extended to the enforcement of these policies. This seems like a reasonable recommendation for any future immigration reform to adopt.

If this policy recommendation were to be adopted in some future immigration reform, its implementation would see to it that any person, neighborhood or workplace be as likely as any other to be investigated, and in a similar manner, by immigration enforcement agencies. The reasoning behind this is that if only certain persons, jobs or neighborhoods are subject to enforcement or disproportionate enforcement, then the citizens who happen to be, live or work in those neighborhoods or perform those particular sorts of jobs will have been given less moral and political consideration than citizens who do not.

But while meeting an equality of burdens standard might be necessary for social trust, it is not sufficient without also having a corresponding commitment to universal protections. Another key component of social trust is that citizens have faith in their political institutions. If political institutions are corrupt or despotic, then, even if all the burdens (e.g., abuses) are equally shared, citizens will only be fulfilling their civic obligations out of fear rather than out of trust. This potential for corruption and despotism suggests that a further standard must be met in order to generate or maintain social trust. This standard will insure social trust by making transparent and limiting the coercive powers of political institutions. To meet this standard a political community does not necessarily need to be prohibited from deploying coercive force, but there must be some mechanisms in place for oversight and restrictions on excessive use when it does deploy force. We can call this the universal protections standard.

As a policy recommendation, it is difficult to say what specific types of oversight or restrictions would be necessary in order to adequately meet this standard, as different communities will have their own unique situation and set of challenges, but there does seem to be at least one universal restriction that this standard should will entail. There must at least be a "presumption of innocence" restriction. This means that all persons should be assumed to be, and treated as though they were, innocent until their guilt has been definitively proven. The justification for this seems obvious; if institutions are allowed to treat citizens as though they are guilty before they have been proven guilty, then there will be little trust, and in fact a whole lot of mistrust, in and within these institutions. 
This means that if a future immigration reform were to adopt something like a universal protections standard, a political community would have to treat all persons present as though they were lawfully present until their status is proven to be irregular. In more concrete terms, if US immigration policy had to adhere to something like a universal protections standard, it would need to give all persons present, regardless of their immigration status, such basic protections as the right to due process, equal protection under the law, freedom from unreasonable searches and seizures, and a right to an attorney, which is currently not the case in removal proceedings. ${ }^{4}$ Protections like these are essential because without them immigration controls could easily infringe on the rights of citizens. ${ }^{5}$ So again, the control a political community has over immigration should be circumvented, not for the sake of noncitizens, but for the sake of not fomenting social mistrust among fellow citizens. ${ }^{6}$

If the two aforementioned standards (equality of burdens and universal protections) were to become part of an immigration policy, they would form a canopy that protects citizens from the excesses of a political community's enforcement mechanisms and in this regard would be essential to the effort of promoting and maintaining social trust. However, one of the consequences of adhering to these standards would be that a political community would lose much of its discretionary control over immigration enforcement. For example, a political community would not, without violating the equality of burdens standard, be able to target certain persons, communities, or occupations with more enforcement, even when it believes that these persons, communities, or occupations are more likely than others to harbor undocumented immigrants. In more concrete terms, this would prohibit raids such as the infamous Postville Raid, which at the time was the largest immigration raid in US history. This raid on a meatpacking plant in Postville, Iowa netted close to 400 undocumented immigrants and in its aftermath close to 1,000 Latino/ as_both citizen and immigrant alike—left Postville (Yu-Hsi Lee 2013). ${ }^{7}$

A political community would also be prohibited from commandeering police officers for immigration enforcement activities, which in the United States is currently a favored enforcement tactic. ${ }^{8}$ The universal protections standard either would prohibit this because of the potential for police abuse (e.g., police could use immigration enforcement duties as an excuse to target people they would otherwise have no excuse to target), because it might make some citizens less likely to come forward to report crimes (e.g., citizens who are the victims of crimes and also happen to live in a household where someone is undocumented might be hesitant to call police) or would make some persons less likely to come forward as 
witnesses or whistleblowers (e.g., the safety of all citizens and the preservation of law and order are dependent on the cooperation of all persons present, regardless of their immigration status).

Now, even if there is disagreement over the details of the two standards I have proposed in this section, the more general point about future immigration reform still seems salient: maintaining moral and political equality among citizens is a key component of social trust, and this equality is put in jeopardy if certain presumptive checks are not placed on a political community's ability to enforce immigration. These checks, while not necessarily entitlements, do provide immigrants with a minimal set of presumptive protections (i.e., immigrant rights in the "negative" sense of rights) that circumvent the discretion a political community enjoys in controlling immigration. This, again, with regard to immigration reform means that increasing enforcement is not a solution. In order for immigration reform to be successful, at least with respect to developing and maintaining social trust, it must make some accommodations for immigrant rights, even if only in a minimalist sense.

\section{Conclusion}

As mentioned in the first section of this chapter, the social trust argument maintains that a political community cannot survive without social trust, and that social trust cannot be achieved or maintained without a political community having discretionary control over immigration. However, as the previous two sections have argued, promoting social trust (or at least abating social mistrust) requires that a political community's immigration policy adhere to sociohistorical circumstances and, at least in a minimalist sense, respect immigrant rights. This critique of the social trust argument is substantially different from prior criticisms that have focused their efforts on developing alternative ways (i.e., resorting to liberal democratic principles or institutions) for keeping the political community together.

While remaining sympathetic to these prior criticisms, this chapter challenged the key assumption of the social trust argument: that discretionary control over immigration can be consistent with a political community achieving or maintaining social trust. If successful, the arguments presented in this chapter not only have undermined the social trust argument, but more importantly have shown why "enforcement first" approaches to immigration reform are, and inevitably will be, unsuccessful. As the case of Latino/as in the United States has shown, social mistrust can arise even in cases where discretionary immigration policy is not motivated by prejudice and even when its intended aim is to rectify 
past injustices. In order to help generate or maintain social trust, adhering to sociohistorical circumstances and respecting immigrant rights must play a more central role in future immigration reforms.

\section{Notes}

1. In this regard, the social trust argument is substantially different from deontological arguments, which defend the claim that "legitimate" states are morally entitled to self-determination, and that a central component of self-determination includes the right not to associate with nonmembers. One such example can be found in the work of Christopher Heath Wellman (see Wellman 2008).

2. For example, Joseph H. Carens and Phillip Cole have made such arguments (see Carens 1997; Cole 2000).

3. James W. Boettcher makes a similar argument, but from the perspective of democratic theory (Boettcher 2013).

4. Under the "Plenary Power Doctrine" the US federal government is free to deport noncitizens without judicial review and because deportation is not considered a punishment, noncitizens also do not have recourse to many important constitutional protections, such as the right to due process, equal protection under the law or the right to have an attorney appointed to them if they cannot afford one while in "removal proceedings" (see Senh 2009; Kanstroom 2007, 16-17).

5. This is an important point to keep in mind because US immigration enforcement has wrongfully deported some of its own citizens and people who were otherwise eligible to remain in the country. In one case, the US citizen wrongly deported was a developmentally handicapped man, whose return trip home was traumatic and very easily could have ended in tragedy (see Powers 2007). A different case did end in tragedy when a wrongly deported man died in a fire inside the Honduran jail where the Honduran immigration agency was holding him (see Guidi 2012).

6. This argument is largely a readaptation of an argument put forth by Michael Blake (see Blake 2003, 224-237).

7. Not all of the Latino/as who left Postville necessarily left the country. This raid can therefore be seen as an example of what Elizabeth Jamison in chapter 7 of this volume refers to as State-based Internal Displacement (Jamison 2015).

8. US federal law currently allows for local law enforcement to be commandeered for immigration enforcement duties under section $287(\mathrm{~g})$ of the Immigration and Nationality Act (1996 Illegal Immigration Reform \& Immigrant Responsibility Act). Also, this linking up of immigration enforcement with local law enforcement has appeared in various state immigration bills. The most notorious of these being Arizona's SB 1070 (see State of Arizona Senate).

\section{References}

1790 Naturalization Act, Chap. 3; 1 Stat 103. 1st Cong., 2nd sess. (March 26, 1790). 1917 Immigration Act, H.R. 10384; Pub.L. 301; 39 Stat. 874. 64th Cong., 2nd sess. (February 5, 1917). 
1924 Immigration Act, H.R. 7995; Pub.L. 68-139; 43 Stat.153. 68th Cong., 1st sess. (May 26,1924).

1943 Magnuson Act, H.R. 3070; Pub.L. 78-199; 57 Stat. 600.78th Cong., 2nd sess. (December 17, 1943).

1965 Immigration and Nationality Act, H.R. 2580; Pub.L. 89-236; 79 Stat. 911. 89th Cong., 2nd sess. (October 3, 1965).

1996 Illegal Immigration Reform \& Immigrant Responsibility Act, H.R. 3610; Pub.L. 104-208; 110 Stat. 3009-546. 104th Cong. (September 30, 1996).

1996 Personal Responsibility and Work Opportunity Reconciliation Act, H.R. 2260; Pub.L. 104-193; 110 Stat. 2105. 104th Cong. (August 22, 1996).

Barvosa, Edwina. 2012. "Applying Latina Feminist Philosophical Approaches to the Self to Reinterpret Anti-Immigrant Politics in America." APA Newsletter on Hispanic/Latino Issues in Philosophy 11(2): 16-21. Accessed May 13, 2014. http:// c.ymcdn.com/sites/www.apaonline.org/resource/collection/60044C96-F3E04049-BC5A-271C673FA1E5/v11n2_Hispanic.pdf.

Blake, Michael. 2003. "Immigration." In A Companion to Applied Ethics, edited. R. G. Frey and Christopher Heath Wellman, 224-237. Oxford: Blackwell Publishing.

Boettcher, James W. 2013. "Immigration Policy and Civic-Political Identity." Public Affairs Quarterly 27(1): 1-23.

Carens, Joseph H. 1997. "Aliens and Citizens: The Case for Open Borders." In The Rights of Minority Cultures, edited by Will Kymlicka, 331-349. Oxford: Oxford University Press.

Chae Chan Ping v. United States, 130 U.S. 581 (1889).

Chinese Exclusion Act, Chap. 126; 22 Stat. 58. 47th Cong., 1st sess. (May 6, 1882).

Chomsky, Aviva. 2014. Undocumented: How Immigration Became Illegal. Boston: Beacon Press.

Cole, Phillip. 2000. Philosophies of Exclusion: Liberal Political Theory and Immigration. Edinburgh: Edinburgh University Press.

De Genova, Nicholas. 2004. "The Legal Production of Mexican 'Illegality'." Latino Studies 2(2): 160-185.

De Leon, Arnoldo. 1979. IN RE Ricardo Rodriguez: An Attempt at Chicano Disfranchisement in San Antonio,1896-1897. San Antonio: Caravel Press.

Delgado, Richard. 2009. "The Law of the Noose: A History of Latino Lynching." Harvard Civil Rights-Civil Liberties Law Review 44(2): 297-312.

Fong Yue Ting v. United States, 149 U.S. 698 (1893).

Gabaccia, Donna R. 2010. "Nations of Immigrants: Do Words Matter?." The Pluralist 5(3): 5-31.

Grant, Madison. 1922. The Passing of the Great Race: The Racial Basis of European History. New York: Charles Scribner's Sons.

Guidi, Ruxandra. 2012. "Honduran LA Resident Accidentally Deported, Then Dies in Prison Fire." Southern California Public Radio. Accessed May 25, 2014, http://www.scpr.org/news/2012/03/02/31481/honduran-resident-los-angeleswrongfully-deported.

Huntington, Samuel. 2004. Who Are We? The Challenges to America's National Identity. New York: Simon \& Schuster Paperbacks.

Jamison, Elizabeth. 2015. "State-Based Immigration Efforts and Internally Displaced Persons (IDPs): An Experiment in Alabama." In Migration Policy Interventions, edited by Harald Bauder and Christian Matheis. New York: Palgrave. 
Johnson, Kevin R. 2005. “The Forgotten 'Repatriation' of Persons of Mexican Ancestry and Lessons for the 'War on Terror'." Pace Law Review 26(1): 1-26.

Kaag, John Jacob. 2008. "We Are Who? A Pragmatic Reframing of Immigration and National Identity." The Pluralist 3(3): 111-131.

Kanstroom, Daniel. 2007. Deportation Nation: Outsiders in American History. Cambridge, MA: Harvard University Press.

Miller, David. 2005. "Immigration: The Case for Limits." In Contemporary Debates in Applied Ethics, edited by Andrew I. Cohen and Christopher Heath Wellman, 193-206. Malden, MA: Blackwell Publishing.

Ngai, Mae. 2004. Impossible Subjects: Illegal Aliens and the Making of Modern America. Princeton, NJ: Princeton University Press.

Orosco, José-Antonio. 2008. Cesar Chavez and the Common Sense of Nonviolence. Albuquerque: University of New Mexico Press.

Pevnick, Ryan. 2009. "Social Trust and the Ethics of Immigration Policy." The Journal of Political Philosophy 17(2): 146-167.

Powers, Kemp. 2007. "Group Says U.S. Citizen Wrongly Deported to Mexico." Reuters. Accessed May 25, 2014. http://www.reuters.com/article/2007/06/11/ us-usa-immigration-deportation-idUSN1118919320070611.

Roediger, David. 2006. Working towards Whiteness: How America's Immigrants Became White. New York: Basic Books.

Schuck, Peter H. 1995. "The Message of Proposition 187." Pacific Law Journal 26: 989-1000.

Senh, Robert. 2009. “The Liberty Rights of Resident Aliens: You Can't Always Get What You Want, But If You Try Sometimes, You Might Find, You Get What You Need." Oregon Review of International Law 11(1): 137-178.

State of Arizona Senate, Forty-Ninth Legislature, Second Regular Session 2010, Senate Bill 1070.

United States v. Brignoni-Ponce, 422 U.S. 873 (1975).

United States v. Martinez-Fuerte, 428 US 543 (1976).

US Immigration and Customs Enforcement. 2014. "Secure Communities." Last modified September 29, 2014. http://www.ice.gov/secure_communities. Accessed August 29, 2014.

Wellman, Christopher H. 2008. "Immigration and Freedom of Association." Ethics 119(1): 109-141.

Wilcox, Shelley. 2004. "Culture, National Identity, and Admission to Citizenship." Social Theory and Practice 30(4): 559-582.

Wilstein, Matt. Rep. "Steve King: Immigrants Mostly 'Evil' Marijuana-Smugglers with 'Calves the Size of Cantaloupes'." Mediaite, July 23, 2013. Accessed December 7, 2014. http://www.mediaite.com/tv/rep-steve-king-immigrantsmostly-evil-marijuana-smugglers-with-calves-the-size-of-cantaloupes/

Yu-Hsi Lee, Esther. "How The Postville Immigration Raid Has Changed Deportation Proceedings." ThinkProgress. May 10, 2013. Accessed December 7, 2014. http:// thinkprogress.org/immigration/2013/05/10/1993661/how-the-postvilleimmigration-raid-has-changed-deportation-proceedings/. 
